\title{
BMJ Open Patterns and predictors of violence against children in Uganda: a latent class analysis
}

\author{
Kelly Clarke, ${ }^{1}$ Praveetha Patalay, ${ }^{2}$ Elizabeth Allen, ${ }^{1}$ Louise Knight, ${ }^{1}$ Dipak Naker, ${ }^{3}$ \\ Karen Devries ${ }^{1}$
}

To cite: Clarke K, Patalay $P$, Allen $\mathrm{E}$, et al. Patterns and predictors of violence against children in Uganda: a latent class analysis. BMJ Open 2016;6:e010443.

doi:10.1136/bmjopen-2015010443

- Prepublication history for this paper is available online. To view these files please visit the journal online (http://dx.doi.org/10.1136/ bmjopen-2015-010443).

Received 3 November 2015 Revised 1 April 2016 Accepted 5 April 2016

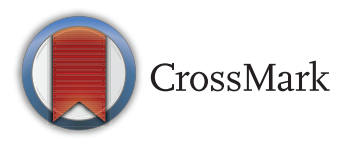

${ }^{1}$ London School of Hygiene and Tropical Medicine, London, UK

${ }^{2}$ University College London, London, UK

${ }^{3}$ Raising Voices, Kampala, Uganda

\section{Correspondence to}

Dr Karen Devries;

karen.devries@Ishtm.ac.uk

\section{ABSTRACT}

Objective: To explore patterns of physical, emotional and sexual violence against Ugandan children.

Design: Latent class and multinomial logistic regression analysis of cross-sectional data.

Setting: Luwero District, Uganda.

Participants: In all, 3706 primary 5, 6 and 7 students attending 42 primary schools.

Main outcome and measure: To measure violence, we used the International Society for the Prevention of Child Abuse and Neglect Child Abuse Screening ToolChild Institutional. We used the Strengths and Difficulties Questionnaire to assess mental health and administered reading, spelling and maths tests.

Results: We identified three violence classes. Class 1 ( $\mathrm{N}=696$ 18.8\%) was characterised by emotional and physical violence by parents and relatives, and sexual and emotional abuse by boyfriends, girlfriends and unrelated adults outside school. Class $2(\mathrm{~N}=975$ $26.3 \%$ ) was characterised by physical, emotional and sexual violence by peers (male and female students). Children in Classes 1 and 2 also had a high probability of exposure to emotional and physical violence by school staff. Class $3(\mathrm{~N}=2035$ 54.9\%) was characterised by physical violence by school staff and a lower probability of all other forms of violence compared to Classes 1 and 2. Children in Classes 1 and 2 were more likely to have worked for money (Class 1 Relative Risk Ratio 1.97, 95\% Cl 1.54 to 2.51; Class $21.55,1.29$ to 1.86), been absent from school in the previous week (Class 11.31, 1.02 to 1.67; Class $21.34,1.10$ to 1.63 ) and to have more mental health difficulties (Class 1 1.09, 1.07 to 1.11; Class 21.11 , 1.09 to 1.13) compared to children in Class 3 . Female sex $(3.44,2.48$ to 4.78$)$ and number of children sharing a sleeping area predicted being in Class 1 . Conclusions: Childhood violence in Uganda forms distinct patterns, clustered by perpetrator and setting. Research is needed to understand experiences of victimised children, and to develop mental health interventions for those with severe violence exposures. Trial registration number: NCT01678846; Results.

\section{INTRODUCTION}

Violence against children, including physical, sexual and emotional abuse, is a global

\section{Strengths and limitations of this study}

- This is one of the first studies to explore the basic patterning of exposure to different forms of violence, from different perpetrators, in a lowincome setting with a high rate of childhood violence.

- This study uses survey data from a large representative sample of primary school children in Uganda, however, results should not be generalised to those outside this group.

- Some children may not have felt comfortable disclosing exposure to sexual violence, possibly due to fear or embarrassment associated with these experiences.

- Owing to the cross-sectional nature of the survey data, we were unable to establish causal relationships between violence exposures and predictors, including mental health.

concern with important health consequences including depression, suicidal behaviour, sexually transmitted infections, risky sexual behaviour and death. ${ }^{1-5}$ Child victims of violence have worse educational outcomes compared to their non-abused peers, and are at increased risk of financial and employment problems in later life. ${ }^{5}$ Children with disabilities and children from socioeconomically disadvantaged families are at increased risk of violence compared to their peers. ${ }^{6}{ }^{7}$ In many settings, rates of sexual violence are higher in girls, while boys may experience more physical violence. ${ }^{7-12}$

Evidence suggests that some children who are exposed to violence are polyvictimised, meaning they are exposed to more than one form of abuse. ${ }^{13}$ Such victims are more likely to report social and economic problems, post-traumatic stress, physical health problems and suicide behaviours, compared to those exposed to only one form of violence. ${ }^{5}{ }^{14}$ Exposure to violence in multiple contexts, the nature of the relationship with the perpetrator and the frequency and 
severity of violence are also likely to affect children's outcomes. $^{13} 15-18$

To date, few studies have explored the basic patterning of exposure to different forms of violence, from different perpetrators, particularly in low and middle-income settings. Two studies, conducted in Denmark and the USA, showed that childhood violence exposures could be grouped according to the type of violence (ie, physical, sexual or emotional), with an additional group of polyvictimised children. ${ }^{19}{ }^{20}$ It also remains unclear how different patterns of exposure relate to health and educational outcomes. This is important, as recent global data suggest substantial variation in the prevalence of exposure to different forms of violence, and variation in patterns of perpetration. ${ }^{21}$ In high-income countries, the prevalence of emotional violence is around $10 \%$, while physical violence estimates range from $4 \%$ to $16 \%$ per year. ${ }^{7}$ Rates are higher in low-income countries, especially in Africa, where $83 \%, 64 \%$ and $43 \%$ of children experience emotional, and moderate and severe physical abuse by their parents, respectively, ${ }^{21}$ and lifetime exposure to sexual violence is $23 \%$ (95\% CI CI 9\% to $33 \%)^{2}$

Our paper focuses on violence against children in Uganda. A recent study conducted in one Ugandan district found that over $90 \%$ of children have experienced physical violence in their lifetime, over half report emotional abuse and $4 \%$ of boys and $13 \%$ of girls report sexual abuse. ${ }^{22}$ Ninety-three per cent of boys and $94 \%$ of girls have ever experienced physical abuse by school staff. ${ }^{22}$ Using data from this study, we aim to identify and characterise patterns of physical, emotional and sexual violence against children in this setting. As far as we are aware, no previous literature has examined these patterns among children in Uganda.

\section{METHODS}

\section{Setting}

We used baseline survey data from the Good Schools Study. ${ }^{23}{ }^{24}$ This study was a cluster-randomised controlled trial of the Good School Toolkit, an intervention developed by Raising Voices, a Ugandan non-profit organisation. ${ }^{24}$ The intervention used a whole school approach and was designed to reduce violence from staff to students and also between students. The primary outcome was physical violence against children by school staff. $^{23}$ The baseline survey took place in June and July 2012, in Luwero District, in the Central Region of Uganda. Luwero comprises both rural and urban areas, and has a population of $458158 .^{25}$ The local language is Luganda. In the 1980s, Luwero district was the site of an insurgency, which involved large-scale murder and starvation of civilians. ${ }^{26}$

\section{Sampling}

Our sampling strategy is described elsewhere. ${ }^{23}$ Briefly, we sampled children through primary schools. From the
268 primary schools in the district, we excluded 97 small schools (with $<40$ registered primary 5 students) and 20 schools with existing governance interventions. The remaining 151 schools were attended by $80 \%$ of all primary 5, 6 and 7 students in Luwero. These schools were stratified based on the gender ratio of students as follows: 13 schools with $>60 \%$ girls; 14 schools with $>60 \%$ boys; and 124 schools with approximately equal numbers of girls and boys. We randomly selected 42 schools, proportional to the size of the stratum. From each school we randomly sampled 130 students from primary 5, 6 and 7, and invited them to participate in the survey. In schools with $<130$ students, all students were invited to participate. Research teams spent 36 days in each school to conduct the survey and made at least one repeat visit to find students who had been absent during that time. We were able to collect data from $77 \%$ of sampled students; $19 \%$ of students were absent from school.

\section{Ethics}

Consent and child protection procedures for this study are described in detail elsewhere. ${ }^{23}{ }^{27}$ Head teachers at each participating school informed staff, students and parents about the study. We notified parents of children at participating schools about the study in several different ways. ${ }^{23}$ Children were allowed to provide consent, rather than assent, because: (1) it was possible to obtain informed consent using a consent form containing a simple description of the study procedure; (2) parents were given the opportunity to opt their children out of the study; and (3) this consent procedure was approved by two independent ethics committees. If children were unable to provide informed consent (eg, they had a disability that meant they could not read the consent form or hear it read aloud, or they did not understand the study procedures described), they were automatically excluded from the study. We developed and implemented a child protection plan to support and link vulnerable children with appropriate services. A trained counsellor was available to any child requesting counselling.

\section{Data collection and instruments}

Through in person interviews, we collected data on child sociodemographics, absence from school, educational performance, mental health and experiences of physical, emotional and sexual violence. All items in the interview were translated into Luganda, and we conducted a three-phase review process. In the first phase, teachers, Raising Voices staff and school staff reviewed the items; in phase 2, we tested items on a sample of $\sim 40$ children from primary schools in Kampala to check understanding and meaning; finally, we surveyed 697 children from Kampala primary schools to assess item distribution and pilot study procedures.

We assessed academic performance through educational tests including word recognition (scoring 1-40), 
timed reading (1-62) and reading comprehension (1-5). We also administered the following group-based tests: silly sentences (testing reading and cognitive ability, scoring 1-20), spelling (1-20) and maths (1-40). A global academic performance score was calculated by dividing the distribution of scores for each test into thirds and allocating one point to children scoring in the bottom third, two points to those scoring in the middle third and three points to those in the top third. We then calculated the mean of these scores over the number of tests completed for each child and labelled the $10 \%$ of children with the lowest mean scores as 'low educational performers'.

To assess children's mental heath, we used the Strengths and Difficulties Questionnaire (SDQ), which has been extensively translated and used in diverse settings. ${ }^{28}$ The questionnaire comprises five subscales: emotional symptoms, conduct problems, hyperactivity/ inattention, peer relationship problems and prosocial behaviour. Each subscale comprises five statements, and children were asked whether they felt the statement was not true (0), somewhat true (1) or certainly true (2). We calculated a SDQ total difficulties score by summing individual subscale scores (excluding the prosocial subscale).

To screen for physical, sexual and emotional violence, we used the International Society for the Prevention of Child Abuse and Neglect Child Abuse Screening Tool-Child Institutional with additional items from the WHO Multi Country Study on Women's Health and Domestic Violence against Women. ${ }^{29} 30$

\section{Analysis}

We used latent class analysis with maximum likelihood estimation to identify distinct patterns or latent classes of violence experienced by children in the sample. ${ }^{31}$ Based on violence items included in the interview, we constructed 14 variables for inclusion in the latent class model (table 1). Physical violence variables incorporated information about perpetrator and severity of violence. For emotional violence variables, we used frequency as a proxy for severity since it was unclear which emotional violence acts children perceived as most severe. Sexual violence variables were coded as binary, due to low rates of reported sexual violence in the sample.

We determined the optimum number of classes by considering the appropriateness and usefulness of classes, in addition to examining well-established statistical model selection criteria including model fit, neatness of classification and model comparison. ${ }^{31}{ }^{32} \mathrm{We}$ used the sample size Adjusted Bayesian Information Criterion (A-BIC), a measure of relative goodness of fit, where lower values indicate better fit. We also used the Lo-Mendell-Rubin Likelihood Ratio Test (LMR-LRT) of goodness of fit, where a non-significant $p$ value indicates that the model with one or fewer classes is preferable, and entropy as a measure of classification quality, with higher entropy values being preferable.
In order to identify predictors of individual class membership, we conducted a multinomial logistic regression analysis, accounting for clustering at the school level. Since the entropy value was relatively low in our selected latent class model, we also conducted a sensitivity analysis including weights for class probability estimates in the regression model. We excluded 77/3706 (2.1\%) individuals from the regression analysis, due to missing data. Although the percentage of excluded individuals differed significantly by class (Class 1: 3.2\%; Class 2: $1.0 \%$; Class 3: 2.2\%; $\chi^{2}$ 9.50, $\left.\mathrm{p}=0.009\right)$, exclusion of such a small proportion of the sample is unlikely to have affected the overall results.

Latent class modelling was conducted using MPlus V.7.0 software. ${ }^{33}$ For all other statistical analyses we used Stata V.12. ${ }^{34}$

\section{RESULTS}

\section{Characteristics of children}

We interviewed 3706 primary school children in 42 schools in Luwero District. Their mean age was 13 years (SD 1.5), ranging from 7 to 18 years. Half $(52.3 \%$, $1937 / 3706)$ the children sampled were girls. Several indicators suggested a substantial proportion of children were from socioeconomically disadvantaged homes: half $(52.9 \%, 1959 / 3706)$ had eaten less than three meals on the previous day and $34.8 \%(1287 / 3706)$ had worked for money outside school. Seven per cent (271/3706) said they had a physical or mental disability. Further information about demographic characteristics of the sample is provided elsewhere. ${ }^{22}$

The mean total SDQ score for the sample was 9.3 (SD, 5.3). Rates of reported violence among children were high. Almost all children $(94.4 \%, 3500 / 3706)$ had experienced some form of physical violence, and $58.3 \%$ (2160) reported experiencing emotional violence. The rate of sexual violence was lower, at $8.9 \%$ $(329 / 3706)$.

\section{Classifying and characterising violence exposures}

We ran latent class models with two to six latent classes. A-BIC, entropy values, as well as the LMR-LRT (table 2) indicated that the three-class model was statistically the most feasible. In addition, the three-class model provided the most meaningful classifications of violence and was hence chosen for further analysis.

Values in table 3 represent the probability, by class, that a child had experienced a given subcategory of violence. The largest class was Class 3, comprising 54.9\% $(2035 / 3706)$ of the children in the sample. The probability of experiencing physical violence by school staff in this class was high (moderate physical violence $87.4 \%$; severe physical violence $0.6 \%$ ), while probabilities associated with other forms of violence were relatively low.

Children in Classes 1 and 2 were polyvictimised, and experienced more severe forms of violence. In addition 
Table 1 Coding of violence variables

\begin{tabular}{|c|c|}
\hline $\begin{array}{l}\text { Type of } \\
\text { violence }\end{array}$ & Variables \\
\hline $\begin{array}{l}\text { Emotional } \\
\text { violence }\end{array}$ & $\begin{array}{l}\text { Emotional abuse by a } \\
\text { parent; emotional abuse by a } \\
\text { peer; emotional abuse by } \\
\text { school staff; emotional abuse } \\
\text { by a non-parent relative; } \\
\text { emotional abuse by others }\end{array}$ \\
\hline
\end{tabular}

Items

Cursed, insulted, shouted at or humiliated you?

Referred to your skin colour, gender, religion, tribe or health problems you have in a hurtful way? Stopped you from being with other children to make you feel bad or lonely? Tried to embarrass you because you were an orphan or without a parent? Embarrassed you because you were unable to buy things? Stole or broke or ruined your belongings? Threatened you with bad marks that you didn't deserve? Accused you of witchcraft? Made you stay outside, for example, in the heat or rain to punish you? Taken your food away from you as punishment? Severe physical violence: Choked you? Severely beat you up? Tried to cut you purposefully with a sharp object? Burnt you as punishment? Moderate physical violence: hurt you or caused pain to you? Slapped you with a hand on your face or head as punishment? Slapped you with a hand on your arm or hand? Twisted your ear as punishment? Twisted your arm as punishment? Pulled your hair as punishment? Hit you by throwing an object at you? Hit you with a closed fist? Hit you with a stick? Caned you? Kicked you? Knocked you on the head as punishment? Made you dig, slash a field or do other labour as punishment? Hit your fingers or hands with an object as punishment? Crushed your fingers or hands as punishment? Made you stand or kneel in a way that hurts to punish you? Forced you to do something that was dangerous? Tied you up with a rope or belt at school?

Sexual Sexual abuse by a peer; violence sexual abuse by a relative; sexual abuse by school staff; sexual abuse by others
Teased you or made sexual comments about your breasts, genitals, buttocks or other body parts? Touched your body in a sexual way or in a way that made you uncomfortable? By 'sexual way,' we mean touching you on your genitals, breasts or buttocks. Showed you pictures, magazines, or movies of people or children doing sexual things? Made you take off your clothes when it was not for a medical reason? Opened or took their own clothes off in front of you when they should not have done so? Kiss you when you didn't want to be kissed? Make you touch their genitals, breasts or buttocks when you didn't want to? Touched your genitals, breasts or buttocks when you didn't want them to? Given you money or things in exchange for doing sexual things? Involved you in making sexual pictures or videos? Threatened or pressured you to have sex or do sexual things with them? Actually made you have sex with them by threatening or pressuring you or by making you afraid of what they might do? Made you have sex with them by physically forcing you (have sex with you)?

\section{Coding}

Coded 2 if any item was experienced many times in the past 12 months or before the past 12 months; 1 if any item was experienced a few or once in the past 12 months or before the past 12 months; 0 if answered no to all items

Coded 2 if any severe physical violence item was experienced; 1 if any moderate item was experienced; 0 if answered no to all items

Coded 1 if answered yes to any item; 0 if no to all items 
Table 2 Statistical criteria for latent class modes with 2-6 latent classes

\begin{tabular}{lllc}
\hline Number of classes & A-BIC & Entropy & LMR-LRT \\
\hline 2 & 35615.057 & 0.514 & $1119.196^{*}$ \\
3 & 35084.842 & 0.602 & $647.894^{\star}$ \\
4 & 35004.205 & 0.585 & 200.585 \\
5 & 34986.703 & 0.655 & 137.768 \\
6 & 34990.520 & 0.687 & 116.557 \\
\hline
\end{tabular}

${ }^{*} \mathrm{p}<0.05$.

A-BIC, Adjusted Bayesian Information Criterion; LMR-LRT,

Lo-Mendell-Rubin Likelihood Ratio Test.

to a high probability of experiencing any form of moderate physical violence by school staff (Class $183.6 \%$; Class $286.8 \%$ ), children in Classes 1 and 2 were more likely to have experienced severe incidents of physical violence (ie, choking, burning or being severely beaten or cut) and emotional violence at school compared to children in Class 3.

Children in Class 1 had a higher probability of having experienced severe and moderate forms of emotional and physical violence by parents and relatives (including siblings) compared to their peers. Children in this class also experienced more sexual and emotional abuse by others, namely, boyfriends, girlfriends and unrelated adults outside school.

Children in Class 2 had a higher probability of experiencing severe and moderate forms of physical, emotional and sexual violence by peers (male and female school students) compared to children in Classes 1 and 3.

Table 4 shows further sociodemographic characteristics of the three classes of violence exposures. Compared to children in Classes 2 and 3, Class 1 comprised a higher proportion of girls and school boarders, and all children in this class had experienced some form of physical violence. Ninety-four per cent (653/ $696)$ and $24.4 \%(170 / 696)$ of children in Class 1 had experienced emotional and sexual violence, respectively, compared to $26.7 \%(544 / 2035)$ and $0.8 \%(17 / 2035)$ of children in Class 3.

Compared to their peers, a smaller proportion of children in Class 2 ate three meals on the previous day, and a higher proportion had ever worked for money, suggesting they may be more socioeconomically disadvantaged compared to children in other classes. Children in Class 2 reported the highest rate of absences on one or more days during the week prior to the survey.

SDQ scores were higher in children in Classes 1 and 2, suggesting that these children experienced more mental health symptoms compared to children in Class 3.

\section{Predicting violence class membership}

We conducted a multinomial logistic regression analysis to identify predictors associated with violence class membership, using Class 3 as the reference class (table 5).
Table 3 Probability estimates of violence exposure by class

\begin{tabular}{|c|c|c|c|}
\hline Number (\% total sample) & $\begin{array}{l}\text { Class } 1 \\
696 \\
(18.8)\end{array}$ & $\begin{array}{l}\text { Class } 2 \\
975 \\
(26.3)\end{array}$ & $\begin{array}{l}\text { Class } 3 \\
2035 \\
(54.9)\end{array}$ \\
\hline \multicolumn{4}{|l|}{ Emotional violence } \\
\hline \multicolumn{4}{|l|}{ Abused by parent } \\
\hline Severe & 10.0 & 0.7 & 0.0 \\
\hline Moderate & 19.0 & 3.1 & 0.1 \\
\hline None & 71.0 & 96.2 & 99.9 \\
\hline \multicolumn{4}{|l|}{ Abused by peers } \\
\hline Severe & 9.9 & 30.6 & 2.2 \\
\hline Moderate & 11.9 & 51.8 & 13.0 \\
\hline None & 78.2 & 17.6 & 84.8 \\
\hline \multicolumn{4}{|l|}{ Abused by school staff } \\
\hline Severe & 13.0 & 14.7 & 1.4 \\
\hline Moderate & 38.5 & 36.7 & 9.4 \\
\hline None & 48.4 & 48.6 & 89.3 \\
\hline \multicolumn{4}{|l|}{ Abused by relatives } \\
\hline Severe & 8.3 & 0.0 & 0.2 \\
\hline Moderate & 11.8 & 1.2 & 1.4 \\
\hline None & 80.0 & 98.8 & 98.3 \\
\hline \multicolumn{4}{|l|}{ Abused by others } \\
\hline Severe & 8.8 & 0.6 & 0.9 \\
\hline Moderate & 17.7 & 0.9 & 3.7 \\
\hline None & 73.6 & 98.5 & 95.4 \\
\hline \multicolumn{4}{|l|}{ Physical violence } \\
\hline \multicolumn{4}{|l|}{ Abused by parent } \\
\hline Severe & 10.0 & 0.2 & 0.0 \\
\hline Moderate & 46.4 & 11.5 & 13.3 \\
\hline None & 52.6 & 88.3 & 86.7 \\
\hline \multicolumn{4}{|l|}{ Abused by peers } \\
\hline Severe & 0.0 & 1.1 & 0.1 \\
\hline Moderate & 24.7 & 64.5 & 12.6 \\
\hline None & 75.3 & 34.3 & 87.3 \\
\hline \multicolumn{4}{|l|}{ Abused by school staff } \\
\hline Severe & 16.4 & 13.0 & 0.6 \\
\hline Moderate & 83.6 & 86.8 & 87.4 \\
\hline None & 0.0 & 0.2 & 12.0 \\
\hline \multicolumn{4}{|l|}{ Abused by relatives } \\
\hline Severe & 0.7 & 0.0 & 0.0 \\
\hline Moderate & 11.5 & 1.6 & 1.1 \\
\hline None & 87.8 & 98.4 & 98.9 \\
\hline \multicolumn{4}{|l|}{ Abused by others } \\
\hline Severe or moderate & 5.7 & 1.9 & 2.3 \\
\hline None & 94.3 & 98.1 & 97.7 \\
\hline \multicolumn{4}{|l|}{ Sexual violence } \\
\hline \multicolumn{4}{|l|}{ Abused by peers } \\
\hline Severe or moderate & 2.7 & 9.0 & 0.5 \\
\hline \multirow{2}{*}{\multicolumn{4}{|c|}{ Abused by relatives (including parents) }} \\
\hline & & & \\
\hline Severe or moderate & 1.4 & 0.3 & 0.1 \\
\hline None & 98.6 & 99.7 & 99.9 \\
\hline \multicolumn{4}{|l|}{ Abused by others } \\
\hline Severe or moderate & 13.8 & 3.4 & 0.4 \\
\hline None & 86.2 & 96.6 & 99.6 \\
\hline \multicolumn{4}{|l|}{ Abused by school staff } \\
\hline Severe or moderate & 4.8 & 3.8 & 0.2 \\
\hline None & 95.2 & 96.2 & 99.8 \\
\hline
\end{tabular}


Table 4 Characteristics of children with violence exposures

\begin{tabular}{|c|c|c|c|c|}
\hline & Class 1 & Class 2 & Class 3 & Overall sample \\
\hline Number (\% total sample) & $696(18.8)$ & $975(26.3)$ & 2035 (54.9) & 3706 \\
\hline Gender female (\%) & $494(71.0)$ & $439(45.0)$ & 1004 (49.3) & 1937 (52.3) \\
\hline \multicolumn{5}{|l|}{$\mathrm{Age}^{\star}$} \\
\hline Mean (SD) & $13.0(1.5)$ & $13.0(1.5)$ & $13.0(1.4)$ & $13.0(1.5)$ \\
\hline Median (range) & $13(9-18)$ & $13(9-18)$ & $13(7-18)$ & $13(7-18)$ \\
\hline \multicolumn{5}{|l|}{ Number of meals eaten yesterday† } \\
\hline 1 meal & $116(16.7)$ & $157(16.1)$ & $243(12.0)$ & $516(13.9)$ \\
\hline 2 meals & $268(38.5)$ & $393(40.3)$ & $782(38.5)$ & $1443(39.0)$ \\
\hline $3+$ meals & $312(44.8)$ & $425(43.6)$ & 1009 (49.6) & $1746(47.1)$ \\
\hline \multicolumn{5}{|l|}{ Number of children sharing sleeping area } \\
\hline 0 & $104(14.9)$ & $126(12.9)$ & $248(12.2)$ & 478 (12.9) \\
\hline 1 & $234(33.6)$ & 291 (29.9) & $532(26.1)$ & 1057 (28.5) \\
\hline $2-4$ & $270(38.8)$ & $422(43.3)$ & $918(45.1)$ & $1610(43.4)$ \\
\hline $5-7$ & 27 (3.9) & $47(4.8)$ & $82(4.0)$ & $156(4.2)$ \\
\hline $8+$ & $61(8.8)$ & $89(9.1)$ & $255(12.5)$ & 405 (10.9) \\
\hline Ever worked for money $\ddagger$ & $240(34.5)$ & 408 (41.9) & $639(31.4)$ & $1287(34.8)$ \\
\hline \multicolumn{5}{|l|}{ Transport to school§ } \\
\hline Other & $25(3.6)$ & $21(2.2)$ & $93(4.7)$ & $139(3.8)$ \\
\hline Walking alone & $169(24.5)$ & $240(25.4)$ & $481(24.2)$ & $890(24.6)$ \\
\hline Walking with someone you know & $423(61.4)$ & $622(65.9)$ & 1269 (63.8) & 2314 (63.9) \\
\hline Boarded at school & 72 (10.5) & $61(6.5)$ & $146(7.3)$ & $279(7.7)$ \\
\hline Disability & $55(7.9)$ & $87(8.9)$ & $129(6.3)$ & $271(7.3)$ \\
\hline Absent on 1 or more days in past week & $159(23.6)$ & $240(24.8)$ & $373(18.7)$ & $772(21.2)$ \\
\hline Low performer on educational tests & $63(9.1)$ & $103(10.6)$ & $212(10.4)$ & $378(10.2)$ \\
\hline SDQ total score M (SD) & $10.6(5.4)$ & $10.9(5.5)$ & $8.2(4.9)$ & $9.3(5.3)$ \\
\hline Physical violence** & $696(100)$ & $975(100)$ & 1829 (89.9) & $3500(94.4)$ \\
\hline Emotional violence ${ }^{\star *}$ & $653(93.8)$ & $963(98.8)$ & $544(26.7)$ & 2160 (58.3) \\
\hline Sexual violence ${ }^{\star *}$ & $170(24.4)$ & $142(14.6)$ & $17(0.8)$ & $329(8.9)$ \\
\hline 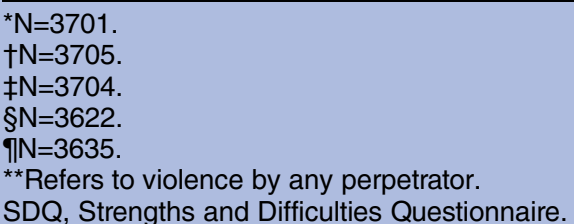 & & & & \\
\hline
\end{tabular}

We found that girls were almost three and a half times more likely to be in Class 1 than in Class 3 (relative risk ratio RRR 3.44, 95\% CI 2.48 to $4.78, \quad \mathrm{p}<0.001)$. Conversely, children who shared their sleeping area with increasing numbers of children were less likely to be in Class 1. The relationship persisted when data from school boarders $(\mathrm{N}=279)$ were omitted from the analysis. In contrast, lower age was significantly associated with Class 2 membership (RRR $0.94,95 \%$ CI 0.88 to 1.00 , $\mathrm{p}=0.044$ ).

Several predictors were associated with both Class 1 and Class 2 violence exposures, including having ever worked for money (Class 1 RRR 1.97, 95\% CI 1.54 to 2.51, p<0.001; Class 2 RRR 1.55, 95\% CI 1.29 to 1.86 , $\mathrm{p}<0.001$ ) and absenteeism in the previous week (Class 1 RRR 1.31, 95\% CI 1.02 to $1.67 \mathrm{p}=0.031$; Class 2 RRR $1.3495 \%$ CI 1.10 to $1.63 \mathrm{p}=0.004)$. SDQ score was higher in children in Class 1 (RRR 1.09, 95\% CI 1.07 to $11, \mathrm{p}<0.001$ ) and Class 2 (RRR $1.1195 \%$ CI 1.09 to 1.13 , p RRR 1.09 , 95\% CI 1.07 to $11, \mathrm{p}<0.001$ ), however, disability and educational performance did not predict violence class membership. Weighting the regression analysis by class probabilities did not change the results.

\section{DISCUSSION}

\section{Summary of main findings}

School children in Uganda are at high risk of all forms of violence, particularly physical and emotional violence by school staff, peers and parents. We identified three classes of children with distinct violence exposures defined by perpetrator and setting. All classes experienced high rates of violence by school staff despite a ban on corporal punishment in Ugandan schools. Class 3 was largest and characterised by physical violence perpetrated by school staff. Children in Class 1 were mainly girls who had experienced multiple and severe forms of violence at home, and sexual violence from 'other' perpetrators. Class 2 comprised children who had experienced a substantial amount of violence from their peers and who were likely to be slightly younger. Children in 
Table 5 Predictors of violence exposure

\begin{tabular}{|c|c|c|c|c|c|c|c|}
\hline & \multirow[b]{2}{*}{ Class 3} & \multicolumn{3}{|l|}{ Class 1} & \multicolumn{3}{|l|}{ Class 2} \\
\hline & & RRR (SE) & $95 \% \mathrm{Cl}$ & p Value & RRR (SE) & $95 \% \mathrm{Cl}$ & p Value \\
\hline Sex (female) & Reference group & $3.44(0.58)$ & 2.48 to 4.78 & $<0.001$ & $0.95(0.11)$ & 0.75 to 1.20 & 0.663 \\
\hline Age & & $1.01(0.04)$ & 0.93 to 1.09 & 0.819 & $0.94(0.03)$ & 0.88 to 1.00 & 0.044 \\
\hline Ever worked for money (yes) & & $1.97(0.24)$ & 1.54 to 2.51 & $<0.001$ & $1.55(0.15)$ & 1.29 to 1.86 & $<0.001$ \\
\hline $\begin{array}{l}\text { Number of meals eaten } \\
\text { yesterday }\end{array}$ & & & & & & & $0.261^{*}$ \\
\hline 3 meals & & \multicolumn{6}{|c|}{ Reference category } \\
\hline 2 meals & & $1.09(0.13)$ & 0.88 to 1.37 & 0.427 & $1.02(0.10)$ & 0.85 to 1.24 & 0.774 \\
\hline 1 meal & & $1.30(0.20)$ & 0.96 to 1.77 & 0.089 & $1.21(0.17)$ & 0.91 to 1.60 & 0.187 \\
\hline $\begin{array}{l}\text { Number of children sharing } \\
\text { sleeping area }\end{array}$ & & & & & & & $0.001^{*}$ \\
\hline 0 & & \multicolumn{6}{|c|}{ Reference category } \\
\hline 1 & & $1.00(0.12)$ & 0.79 to 1.26 & 0.987 & $1.11(0.12)$ & 0.90 to 1.38 & 0.330 \\
\hline $2-4$ & & $0.62(0.09)$ & 0.47 to 0.81 & 0.001 & $0.89(0.10)$ & 0.71 to 1.12 & 0.329 \\
\hline $5-7$ & & $0.65(0.16)$ & 0.39 to 1.06 & 0.086 & $1.04(0.24)$ & 0.66 to 1.65 & 0.868 \\
\hline $8+$ & & $0.53(0.13)$ & 0.33 to 0.85 & 0.009 & $0.70(0.16)$ & 0.45 to 1.08 & 0.109 \\
\hline Disability (yes) & & $1.04(0.17)$ & 0.75 to 1.43 & 0.818 & $1.17(0.15)$ & 0.90 to 1.51 & 0.235 \\
\hline $\begin{array}{l}\text { Absent on } 1 \text { or more days in } \\
\text { past week }\end{array}$ & & $1.31(0.17)$ & 1.02 to 1.67 & 0.031 & $1.34(0.14)$ & 1.10 to 1.63 & 0.004 \\
\hline $\begin{array}{l}\text { Low performer on educational } \\
\text { tests (yes) }\end{array}$ & & $0.70(0.13)$ & 0.49 to 1.02 & 0.063 & $0.78(0.13)$ & 0.56 to 1.09 & 0.146 \\
\hline SDQ total score & & $1.09(0.01)$ & 1.07 to 1.11 & $<0.001$ & $1.11(0.01)$ & 1.09 to 1.13 & $<0.001$ \\
\hline
\end{tabular}

Classes 1 and 2 experienced violence in multiple contexts, for example, children in Class 1 were at risk of exposure to violence at home and in school. Children in Classes 1 and 2 also had worse mental health outcomes relative to children in Class 3 .

\section{Comparison with other studies}

Few studies have examined childhood violence using latent class analysis. A retrospective study of young adults in Denmark identified four violence classes: non-abused, psychologically abused, sexually abused and a class experiencing multiple abuse types. ${ }^{19}$ Nooner et al characterised four exposures to physical and sexual violence among children in the USA, however, emotional violence was not included. ${ }^{20}$ In both these studies, the majority of sampled children had not been exposed to violence, and information on perpetrator was not incorporated into the analyses. In contrast, violence classes in our study were mainly defined by perpetrator and setting, rather than type or severity of violence. Since the prevalence of violence in our sample was comparatively high, we did not identify a non-abused class and polyvictimisation was common.

We found that children in Classes 1 and 2 had more mental health difficulties than children in Class 3. This is consistent with studies suggesting that individuals with cross-contextual violence exposures by multiple perpetrators may have poorer mental health. ${ }^{17}{ }^{18}$ Witnessing violence -for example, community or domestic violence-may reduce or strengthen the association between children's violence exposures and mental health, however, we did not investigate these effects in the study. ${ }^{35} 36$ A school-based intervention in Luwero District reduced violence against children by school staff but did not significantly improve children's mental health. ${ }^{24}$ One possible explanation for this is that, in addition to violence by school staff, many children were also experiencing violence in other contexts, which was not specifically addressed by the intervention. This suggests there is a need for treatment of the effects of multiple co-occurring types of violence from multiple perpetrators in this setting, which is directly related to the patterns of violence described in this study.

Our finding that girls are more likely to experience multiple and severe forms of violence from family members, and sexual violence from others, is consistent with national studies reporting higher rates of domestic violence against adult women compared to those against men in many African settings. ${ }^{37}$ Girls may be at greater risk due to spending more time in the home and being physically weaker than their brothers. Son preference may also be a factor in certain cultural contexts. ${ }^{38-41}$ Early intervention is necessary to prevent re-victimisation of and long-term effects for girls, including interpersonal violence, sexual coercion, alcohol and drug abuse and mental health problems. ${ }^{42} 43$

Children in Class 2, which was characterised by a higher risk of peer-related violence, were more likely to have been absent in the previous week, suggesting absenteeism may be a coping mechanism. These children were at higher risk of sexual violence compared to their peers, and had poorer mental health than children 
with school staff physical violence exposures in Class 3. Long-term effects of childhood sexual violence include substance misuse, early sexual debut, more sexual partners, trading sex for financial gain and less use of contraception, as well as interpersonal difficulties, post-traumatic stress disorder and suicidal behaviour. ${ }^{4-51}$ Our results imply that interventions to reduce peer-related violence among primary school children could be beneficial for mental health, as well as for sexual and reproductive health in this population.

Although previous studies have reported associations between educational performance and violence exposure, low performance on educational tests did not predict class membership in our study. ${ }^{10}{ }^{52}$ This could be because children respond differently to violence, for example, some children exposed to violence at home may immerse themselves in their schoolwork whereas others may withdraw. Furthermore, children may be victimised by peers because they underachieve at school whereas others may be bullied for overachieving. Additional research is needed to investigate relationships between educational performance and violence exposure among children.

\section{Implications}

These novel findings suggest that patterning of childhood violence in this context is clustered by perpetrator and setting. Research is needed to understand pathways to perpetration, and how the nature of the perpetrator's relationship to the victim might determine the health and social effects of violence. Interventions targeting groups of perpetrators, rather than victims, may be beneficial. Since most of the children in our study were exposed to school staff physical and/or peerrelated violence, school-based interventions for teachers and students could potentially reduce the main sources of childhood violence in this setting. Interventions targeting perpetration by parents could potentially reduce some important violence exposures for children in Class $1 .^{53}$

Further research is necessary to understand associations between different forms of violence for the group of mainly girls experiencing severe violence at home and sexual abuse from other perpetrators. For example, are girls from violent families more vulnerable to perpetrators of sexual violence outside the home? Alternatively, are girls who have been sexually victimised outside the home more likely to be punished and stigmatised by their family? Understanding these pathways would help to design effective interventions to support children in this class.

\section{Limitations}

Our study has several limitations. First, it is likely that sexual violence was under-reported. Subsequent surveys using alternative approaches to asking about sexual violence have estimated higher rates in the same population of children. ${ }^{24}$ Second, the latent classes of violence exposure identified in this study are statistical constructs, requiring further validation and characterisation using qualitative research methods. Third, our study includes only children enrolled in primary school who attended school during the survey. Results might not be generalisable to children who were absent or not enrolled, and who may represent a more vulnerable group. Last, due to the cross-sectional nature of our data, we were unable to establish causal relationships between class membership and predictors.

\section{CONCLUSIONS}

Overlapping experiences of physical, emotional and sexual violence, clustered by perpetrator and setting, are common among children in Uganda. Future interventions addressing both, perpetrators and victims are necessary for safer schools and homes, and to improve children's mental health.

Acknowledgements The author would like to thank Professor Bianca DeStavola for her advice concerning latent class analysis. The study was financially supported by the Hewlett Foundation, MRC, DfID and Wellcome Trust, who had no role in the design and conduct of the study, collection, management, analysis and interpretation of the data, and preparation, review, or approval of the manuscript, nor in the decision to submit the manuscript for publication. This paper was prepared under the Know Violence in Childhood: Global Learning Initiative (http://www.knowviolenceinchildhood. org/).

Contributors $\mathrm{KC}$ and $\mathrm{KD}$ conceptualised and designed the study. KC and PP conducted the statistical analysis and KC wrote the first draft of the manuscript. All the authors reviewed and contributed to the manuscript and approved the final draft for submission.

Funding This work was funded by MRC, DfID, Wellcome Trust and Hewlett Foundation.

Competing interests DN developed the Good School Toolkit. This article uses data from the baseline survey of the trial evaluating the Toolkit.

Ethics approval The London School of Hygiene and Tropical Medicine, and the Uganda National Council for Science and Technology provided ethical approval for the trial.

Provenance and peer review Not commissioned; externally peer reviewed.

Data sharing statement No additional data are available.

Open Access This is an Open Access article distributed in accordance with the terms of the Creative Commons Attribution (CC BY 4.0) license, which permits others to distribute, remix, adapt and build upon this work, for commercial use, provided the original work is properly cited. See: http:// creativecommons.org/licenses/by/4.0/

\section{REFERENCES}

1. Andrews G, Corry J, Slade T, et al. Child sexual abuse. In: Ezzat MLA, Rodgers A, Murray CJL, eds. Comparative quantification of health risks: global and regional burden of disease attributable to selected major risk factors. Geneva: World Health Organisation, 2004:1851-940.

2. Brown DW, Riley L, Butchart A, et al. Exposure to physical and sexual violence and adverse health behaviours in African children: results from the Global School-based Student Health Survey. Bull World Health Organ, 2009;87:447-55.

3. Hillis S, Mercy JA, Amobi A, et al. Global prevalence of past-year violence against children: a systematic review and minimum estimates. Pediatrics 2016;137:1-13.

4. Norman RE, Byambaa M, De R, et al. The long-term health consequences of child physical abuse, emotional abuse, and 
neglect: a systematic review and meta-analysis. PLoS Med 2012;9: e1001349.

5. UNICEF. Hidden in plain sight: a statistical analysis of violence against children. New York: UNICEF, 2014.

6. Butchart A, Phinney Harvey A, Kahane T, et al. Preventing child maltreatment: a guide to action and generating evidence. Geneva: World Health Organization and International Society for Prevention of Child Abuse and Neglect, 2006.

7. Gilbert R, Widom CS, Browne K, et al. Burden and consequences of child maltreatment in high-income countries. Lancet 2009;373:68-81.

8. Finkelhor $\mathrm{D}$. The international epidemiology of child sexual abuse. Child Abuse Negl 1994;18:409-17.

9. Pereda N, Guilera G, Forns M, et al. The international epidemiology of child sexual abuse: a continuation of Finkelhor (1994). Child Abuse Negl 2009;33:331-42.

10. Pinheiro PS. World report on violence against children. New York: United Nations, 2006

11. Runyan $D$, Wattam $C$, Ikeda $R$, et al. Child abuse and neglect by parents and other caregivers. In: Krug EG, Dahlberg LL, Mercy JA, et al, eds. World report on violence and health. Geneva: World Health Organisation, 2002:59-86.

12. Stoltenborgh M, van ljzendoorn MH, Euser EM, et al. A global perspective on child sexual abuse: meta-analysis of prevalence around the world. Child Maltreat 2011;16:79-101.

13. Finkelhor D, Ormrod RK, Turner HA. Poly-victimization: a neglected component in child victimization. Child Abuse Negl 2007;31:7-26.

14. Bryant SL, Range LM. Suicidality in college women who were sexually and physically abused and physically punished by parents. Violence Vict 1995;10:195-201.

15. Beitchman $\mathrm{JH}$, Zucker $\mathrm{KJ}$, Hood JE, et al. A review of the long-term effects of child sexual abuse. Child Abuse Negl 1992;16:101-18.

16. Bryant SL, Range LM. Type and severity of child abuse and college students' lifetime suicidality. Child Abuse Negl 1997;21:1169-76.

17. Holt MK, Espelage DL. A cluster analytic investigation of victimization among high school students. J Appl Sch Psychol 2003;19:81-98.

18. Holt MK, Finkelhor D, Kantor GK. Multiple victimization experiences of urban elementary school students: associations with psychosocial functioning and academic performance. Child Abuse Negl 2007;31:503-15.

19. Armour C, Elklit A, Christoffersen MN. A latent class analysis of childhood maltreatment: identifying abuse typologies. J Loss Trauma: International Perspectives on Stress and Coping 2014;19:23-9.

20. Nooner KB, Litrownik AJ, Thompson R, et al. Youth self-report of physical and sexual abuse: a latent class analysis. Child Abuse Negl 2010;34:148-54.

21. Akmatov MK. Child abuse in 28 developing and transitional countries-results from the Multiple Indicator Cluster Surveys. Int J Epidemiol 2011;40:219-27.

22. Devries KM, Child JC, Allen E, et al. School violence, mental health, and educational performance in Uganda. Pediatrics 2014;133: e129-37.

23. Devries KM, Allen E, Child JC, et al. The Good Schools Toolkit to prevent violence against children in Ugandan primary schools: study protocol for a cluster randomised controlled trial. Trials 2013;14:232.

24. Devries KM, Knight L, Child JC, et al. The Good School Toolkit for reducing physical violence from school staff to primary school students: a cluster-randomised controlled trial in Uganda. Lancet Global Health 2015;385:e378-86.

25. Uganda Bureau of Statistics. The National Population and Housing Census 2014 - Provisional Results, Kampala, Uganda, 2014.

26. Gersony R. The anguish of Northern Uganda: results of a field-based assessment of the civil conflicts in Northern Uganda. Kampala, Uganda: Mission USEaU, 1997.

27. Child JC, Naker D, Horton J, et al. Responding to abuse: children's experiences of child protection in a central district, Uganda. Child Abuse Negl 2014;38:1647-58.

28. Goodman R, Ford T, Simmons $\mathrm{H}$, et al. Using the Strengths and Difficulties Questionnaire (SDQ) to screen for child psychiatric disorders in a community sample. Br J Psychiatry 2000;177:534-9.
29. International Society for the Prevention of Child Abuse and Neglect. ICASTC: the ISPCAN Child Abuse Screening Tool-Child Version. Manual and proposed guidelines for pilot administration. Aurora International Society for the Prevention of Child Abuse and Neglect, 2006.

30. Garcia-Moreno $\mathrm{CJ}$, Ellsberg $\mathrm{H}$, Heise $\mathrm{M}$, et al. WHO multi-country study on womens health and domestic violence against women. Geneva, Switzerland: World Health Organization, 2005.

31. Muthen B, Muthen L. Integrating person-centered and variable-centered analysis: growth mixture modeling with latent trajectory classes. Alcohol Clin Exp Res 2000;24:882-91.

32. Vermunt JK, Magidson J. Latent GOLD 4.0 User's Guide. Belmont, Massachusetts: Statistical Innovations Inc, 2005.

33. Muthén LK, Muthén BO. Mplus user's guide (7th edition). Los Angeles, CA: Muthén \& Muthén, 2012.

34. StataCorp. Stata Statistical Software: Release 12. College Station, TX StataCorp LP, 2011.

35. Mrug S, Windle M. Prospective effects of violence exposure across multiple contexts on early adolescents' internalizing and externalizing problems. J Child Psychol Psychiatry 2010;51:953-61.

36. Mrug S, Loosier PS, Windle M. Violence exposure across multiple contexts: individual and joint effects on adjustment. $A m \mathrm{~J}$ Orthopsychiatry 2008;78:70-84.

37. Andersson N, Ho-Foster A, Mitchell S, et al. Risk factors for domestic physical violence: national cross-sectional household surveys in eight southern African countries. BMC Womens Health 2007;7:11

38. Watts C, Zimmerman C. Violence against women: global scope and magnitude. Lancet 2002;359:1232-7.

39. Sen A. Missing women. BMJ 1992;304:587-8.

40. Coale $\mathrm{AH}$. Excess female mortality and the balance of the sexes in the population: an estimate of the number of "missing females". Popul Dev Rev 1991;17:517-23.

41. Cohen A. Excess female mortality in India: the case of Himachal Pradesh. Am J Public Health 2000;90:1369-71.

42. Coid J, Petruckevitch A, Feder G, et al. Relation between childhood sexual and physical abuse and risk of revictimisation in women: a cross-sectional survey. Lancet 2001;358:450-4.

43. Heise L, Ellsberg M, Gottmoeller M. A global overview of gender-based violence. Int J Gynaecol Obstet 2002;78(Suppl 1): S5-14

44. Felitti VJ, Anda RF, Nordenberg D, et al. Relationship of childhood abuse and household dysfunction to many of the leading causes of death in adults. The adverse childhood experiences (ACE) study. Am J Prev Med 1998;14:245-58.

45. Fergusson DM, Horwood LJ, Lynskey MT. Childhood sexual abuse, adolescent behaviours and sexual revictimization. Child Abuse Negl 1997:21:789-803

46. Fiscella K, Kitzman HJ, Cole RE, et al. Does child abuse predict adolescent pregnancy? Pediatrics 1998;101(Pt 1):620-4.

47. Handwerker W. Gender power differences between parents and high-risk sexual behaviour by their children: AIDS/STD risk factors extend to a prior generation. $J$ Women's Health 1993;2:301-16.

48. Walker E, Gelfand A, Katon W, et al. Adult health status of women HMO members with histories of childhood abuse and neglect. Am J Med 1999;107:332-9.

49. Jewkes R, Vundule C, Maforah F, et al. Relationship dynamics and adolescent pregnancy in South Africa. Soc Sci Med 2001;52:733-44.

50. Devries $\mathrm{K}$, Watts $\mathrm{C}$, Yoshihama $\mathrm{M}$, et al. Violence against women is strongly associated with suicide attempts: evidence from the WHO multi-country study on women's health and domestic violence against women. Soc Sci Med 2011;73:79-86.

51. Briere N, Elliott DM. Immediate and long-term impacts of child sexual abuse. Future Child 1994;4:54-69.

52. Boden JM, Horwood LJ, Fergusson DM. Exposure to childhood sexual and physical abuse and subsequent educational achievement outcomes. Child Abuse Negl 2007;31:1101-14.

53. Macmillan $\mathrm{HL}$, Wathen $\mathrm{CN}$, Barlow J, et al. Interventions to prevent child maltreatment and associated impairment. Lancet 2009;373:250-66 